\title{
ВЫЯВЛЕНИЕ МУТАЦИИ SER450LEU В ГEHE RPOB MYCOBACTERIUM TUBERCULOSIS МЕТОДОМ АЛЛЕЛЬ-СПЕЦИФИЧНОЙ ИЗОТЕРМИЧЕСКОЙ ПЕТЛЕВОЙ АМПЛИФИКАЦИИ ДНК
}

\author{
М. Л. Филипенко ${ }^{\circledR}$, И. П. Оскорбин ${ }^{1}$, Е. А. Храпов ${ }^{1}$, Д. В. Шамовская ${ }^{1}$, А. Г. Чередниченко², Я. Ш. Шварц² \\ ${ }^{1}$ Институт химической биологии и фундаментальной медицины СО РАН, Новосибирск, Россия \\ 2 Новосибирский научно-исследовательский институт туберкулеза, Новосибирск, Россия
}

\begin{abstract}
Для выявления генетических мутаций широко используют достаточно трудоемкий и дорогостоящий метод полимеразной цепной реакции (ПЦР). Целью работы было оценить возможность применения двух схем метода аллель-специфичной изотермической петлевой амплификации (Іоор-теdiated isothermal amplification, LAMP) для выявления мутации TCG/TTG (S450L) в гене rроB Мусоbacterium tuberculosis. Использовали 48 клинических изолятов M. tuberculosis и 11 образцов мокроты, выбранных случайным образом и полученных в микробиологической лаборатории г. Новосибирска от пациентов с впервые выявленным заболеванием. Показано, что применение схемы анализа с использованием аллель-специфичного праймера FIP по сравнению c F3 имеет лучшую разрешающую способность: разница между временем амплификации мутации и аллеля дикого типа составила $22 \pm 2,4$ против $13 \pm 4,1$ мин (p = 0,0011). При использовании 100 геном-эквивалентов ДНК истинно положительный сигнал (амплификация гена гроВ с мутацией при использовании соответствующего аллель-специфического праймера) детектировался после 29,4 \pm 3,4 мин. Положительный сигнал визуализировался после добавления в реакцию SYBR Green I, как при освещении дневным светом, так и при использовании трансиллюминатора с УФ-излучением. C помощью разработанного нами метода была проанализирована выборка ДНK 20 RIFR изолятов M. tuberculosis, Hecyщих мyтацию Ser450Leu в гене rpoB, 10 RIFR изолятов, несущих другие мутации в гене rроB, а также $18 \mathrm{RIF}^{\mathrm{s}}$ изолятов без мутаций; наличие мутаций в образцах было определено с помощью классического секвенирования по Сенгеру. Чувствительность и специфичность LAMP для выявления мутации Ser450Leu в гене rрoB составили 100\%. Данный подход позволяет использовать в качестве ДНК грубые лизаты микобактерий, что сокращает тотальное время анализа до 1,5 ч.
\end{abstract}

Ключевые слова: Mycobacterium tuberculosis, лекарственная устойчивость, мутации, рифрампицин, ген гроВ, изотермическая петлевая амплификация, LАМР Финансирование: работа выполнена при финансовой поддержке проекта базового бюджетного финансирования № VI.62.1.5 «Синтетическая биология: разработка средств манипуляции генетическим материалом и создание перспективных препаратов для терапии и диагностики" (0309-2018-0003).

Информация о вкладе авторов: М. Л. Филипенко - общий замысел работы, планирование экспериментов, анализ результатов экспериментов, написание статьи; И. П. Оскорбин — написание статьи; Е. А. Храпов - проведение экспериментов; Д. В. Шамовская - проведение экспериментов; А. Г. Чередниченко - анализ результатов экспериментов; Я. Ш. Шварц - планирование и анализ результатов экспериментов.

Соблюдение этических стандартов: исследование одобрено комитетом по медицинской этике Института химической биологии и фундаментальной медицины СО РАН (№ 4 от 9 апреля 2009 г.). Все пациенты подписали добровольное информированное согласие на участие в исследовании.

$\triangle$ Для корреспонденции: Максим Леонидович Филипенко

пр. академика Лаврентьева, д. 8/2, г. Новосибирск, 630090; mlfilipenko@gmail.com

Статья получена: 07.12.2018 Статья принята к печати: 25.02.2019 Опубликована онлайн: 09.03.2019

DOI: 10.24075/vrgmu.2019.007

\section{DETECTION OF SER450LEU MUTATION IN RPOB GENE OF MYCOBACTERIUM TUBERCULOSIS BY ALLELE-SPECIFIC LOOP-MEDIATED ISOTHERMAL DNA AMPLIFICATION METHOD}

Filipenko ML ${ }^{1} \otimes$, Oscorbin $\mathrm{P}^{1}$, Khrapov EA ${ }^{1}$, Shamovskaya DV ${ }^{1}$, Cherednichenko $A G^{2}$, Shvartz YaSh ${ }^{2}$

${ }^{1}$ Institute of Chemical Biology and Fundamental Medicine, Novosibirsk, Russia

2 Novosibirsk Tuberculosis Research Institute, Novosibirsk, Russia

To identify genetic mutations a rather time-consuming and expensive method of polymerase chain reaction (PCR) is widely used. The aim of the present work was to evaluate the possibility of using the two schemes of the method of allele-specific isothermal loop amplification (LAMP) to detect the TCG/TTG (S450L) mutation in the rpoB gene of Mycobacterium tuberculosis. 48 clinical isolates of $M$. tuberculosis and 11 samples of sputum were used, randomized and obtained in the microbiological laboratory of the city of Novosibirsk from incident patients. It is shown that the use of an analysis scheme using the allele-specific primer FIP compared to F3 has the best resolution: the difference between the amplification time of the mutation and the wild type allele was $22 \pm 2,4$ versus $13 \pm 4,1$ minutes $(p=0,0011)$. When using 100 DNA genomic equivalents a true positive signal (amplification of the rpoB gene with a mutation using the corresponding allele-specific primer) was detected after 29,4 $\pm 3,4$ minutes. A positive signal was visualized after adding SYBR Green I to the reaction, both when illuminated with daylight and when using a UV transilluminator. Using the developed method the DNA sample of $20 \mathrm{RIF}^{\mathrm{R}}$ isolates from M. tuberculosis was analyzed containing the Ser450Leu mutation in the rpoB gene, $10 \mathrm{RIF}^{\mathrm{R}}$ isolates containing other mutations in the rpoB gene and $18 \mathrm{RIFs}^{\mathrm{s}}$ isolates without any mutations; the presence of mutations in the samples was determined using classical Sanger sequencing. The sensitivity and specificity of LAMP for detecting a Ser450Leu mutation in the rpoB gene was $100 \%$. This approach allows the use of crude lysates of mycobacteria as DNA, which reduces the total analysis time to 1,5 hour.

Keywords: Mycobacterium tuberculosis, drug resistance, rifampicin, rpoB gene, isothermal loop amplification, LAMP

Funding: the study was done with the financial support of the basic budgetary financing project № VI.62.1.5 «Synthetic biology: development of tools for the genetic material manipulation and creation of promising drugs for therapy and diagnostics» (0309-2018-0003).

Author contribution: Filipenko ML created a general concept of the study, planned experiments, analyzed the results and participated in the writing of this article; Oscorbin IP participated in the writing of this article; Khrapov EA conducted experiments; Shamovskaya DV conducted experiments; Cherednichenko AG analyzed the experiments results; Shvartz YaSh was involved in planning and analyzed the experiments results.

Compliance with ethical standards: the study was approved by the Ethics Committee of Institute of Chemical Biology and Fundamental Medicine (Protocol 4 dated April 09, 2009). All patients signed a voluntary informed consent to participate in the study.

$\triangle$ Correspondence should be addressed: Maxim L. Filipenko

Lavrentyev Prospect 8/2, Novosibirsk, 630090; mlfilipenko@gmail.com

Received: 07.12.2018 Accepted: 25.02.2019 Published online: 09.03.2019

DOI: 10.24075/brsmu.2019.007 
В течение многих столетий туберкулез входит в число самых сложных в терапии инфекционных заболеваний с высокой летальностью. Сейчас лекарственно устойчивые (ЛУ) изоляты M. tuberculosis представляют собой угрозу для здравоохранения: затрудняют консервативное лечение, приводят к инвалидизации пациентов, при этом наблюдается рост и распространение ЛУ-штаммов среди здорового населения. Это обусловливает необходимость разработки эффективных и, по возможности, простых методов выявления лекарственной резистентности микобактерий Одним из широко используемых противотуберкулезных препаратов первого ряда при лечении туберкулеза является рифампицин. Резистентность к нему часто рассматривают как суррогатный маркер множественной лекарственной устойчивости (МЛУ) микобактерий туберкулезного комплекса (МТБ) [1]. Рифампицин был введен в лечебную практику фтизиатров в 1972 г. Он высокоэфффективен против МТБ, минимальная ингибиторная концентрация (MIC) рифампицина составляет 0,1-0,2 мкг/мл [2]. В сочетании с изониазидом и пиразинамидом рифампицин лежит в основе химиотерапии туберкулезной инфекции.

Клеточной мишенью рифампицина служит фермент ДНК-зависимая РНК-полимераза, исключительно консервативный среди бактерий и архей. Подавляющее большинство мутаций, обусловливающих устойчивость к рифампицину, локализуется в трех регионах гена rроВ, кодирующего бета-субъединицу РНК-полимеразы: кластере I (кодирует 512-534 позиции аминокислот), кластере II (563-574) и кластере III (687). В 95\% случаев мутации затрагивают кластер I или так называемый регион, детерминирующий резистентность к рифампицину (RRDR) размером 81 п.н. Этот регион соответствует кодонам 426-452 у МТБ и 507-533 у Escherichia coli. Традиционно обозначаемые по номенклатуре E. coli мутации в кодонах 521, 526, 531 и 533 (позиции 440, 445, 450 и 452 в гене гроВ МТБ) наиболее часто встречаются у устойчивых к рифампицину микобактерий туберкулеза [3].

Аминокислотные замены в положении 526 и 531 ведут к резистентности к высоким дозам рифампицина. Аминокислотная замена Ser450Leu (S450L, номенклатура гена МТБ, которая в дальнейшем будет использована в настоящей статье) доминирует среди всех других замен, определяя резистентность у 30-70\% устойчивых к рифампицину $\left(\mathrm{RIF}^{\mathrm{R}}\right)$ изолятов (с медианой около 60\%) [3]. Это делает мутацию S450L (TCG/TTG) наиболее значимым кандидатом для валидации самых разнообразных методов генетического скрининга с целью выявления резистентности МТБ к рифампицину $[4,5]$.

Сегодня наиболее часто используемым методом выявления генетических мутаций является полимеразная цепная реакция (ПЦР). Метод прост в исполнении и достаточно надежен. Модификации ПЦР с использованием мониторирования специфичных ампликонов путем детекции накопления флуоресцентного сигнала (ПЦР в реальном времени) делают анализ гомогенным и позволяют избежать дополнительных манипуляций с ампликоном вне пробирки. Однако ПЦР выполняют с помощью достаточно сложных и дорогостоящих приборов. Это послужило причиной для разработки альтернативных методов амплификации нуклеиновых кислот, в первую очередь осуществимых в изотермических условиях [6].

В 2000 г. была разработана технология изотермической петлевой амплификации (loop-mediated isothermal amplification, LAMP). Первоначально метод предполагал использование двух пар праймеров (внешней и внутренней) и ДНК-полимеразы с цепь-вытесняющей активностью [7]. Позднее разработчиками была введена дополнительная пара праймеров для улучшения кинетики амплисикации

LAMP по специфичности и чувствительности (предел чувствительности до нескольких молекул ДНК) сравнима с ПЦР, а в некоторых случаях превосходит ее. Отмечена также повышенная устойчивость LAMP $\mathrm{k}$ действию ингибиторов ПЦР [8]. Для детекции результатов LAMP можно использовать подходы, основанные на разных принципах. В первую очередь это измерение оптической плотности за счет образующегося при синтезе ДНК пирофосфата магния [9], или флуоресценции при введении интеркалирующих красителей [9], модификации праймеров [10] или введения флуоресцентно-меченных зондов [11], а также колориметрическая детекция металлчувствительными красителями за счет связывания ионов магния пиросооссатом [12].

K настоящему времени проведено значительное количество исследований, посвященных разработке тестсистем для выявления МТБ с использованием LAMP [13]. Коммерческий набор Lоopamp MTBC Detection Kit (Eiken Chemical Company Ltd; Япония), основанный на LAMP, был отмечен ВОЗ как возможная замена микроскопических исследований для диагностики туберкулеза [14]. Он был рекомендован также как дополнительный к микроскопии тест при диагностике взрослых с клиническими симптомами туберкулеза, в том числе для диагностики негативных по результатам микроскопии пациентов. Однако применение LAMP для выявления мутаций МТБ, вызывающих лекарственную резистентность, до настоящего времени описано не было.

Целью нашей работы было разработать метод выявления мутации TCG/TTG (S450L) в гене rpoB Mycobacterium tuberculosis для детекции устойчивости к рифампицину без применения дорогостоящего оборудования, а также провести оценку эффективности двух типов дизайна построения аллель-специфичной изотермической петлевой амплификации (AS-LAMP) и определить аналитические характеристики оптимальной системы на представительной выборке ДНК изолятов МТБ.

\section{МАТЕРИАЛЫ И МЕТОДЫ}

\section{Клинические изоляты}

Клинические изоляты M. tuberculosis (48 изолятов), а также 11 образцов мокроты были выбраны случайным образом и получены в микробиологической лаборатории НИИТуб, г. Новосибирск от пациентов, проживающих в г. Новосибирске и Новосибирской области и проходивших обследование в 2009-2011 гг. Взятие и обработку мокроты осуществляли в соответствии с приказом № 109 МЗ РФ от 21 марта 2003 г. (ред. от 29 октября 2009 г.). Критерии включения пациентов в исследование: мужчины и женщины любого возраста; впервые выявленное заболевание; наличие устойчивости к рифампицину. Критерии исключения: не впервые выявленное заболевание; отсутствие устойчивости к рифампицину. Устойчивость к рифампицину (40 мкг/мл) определяли в соответствии с методом абсолютных концентраций на среде Левенштейна-Йенсена. Устойчивость изолятов к рифампицину определяли в флюорометрической системе «BACTEC MGIT 960» (Becton-Dickinson; CША). Грубые лизаты бактериальных клеток, а также ДНК из 
бактериальных колоний изолятов получали нагреванием в 300 мкл буфера, содержащего 10 мМ тетрабората натрия (рН 9.5) и 1\% 2-метоксиэтанола, в течение 10 мин при $98^{\circ} \mathrm{C}$ с последующим центрифугированием для осаждения клеточного дебриса.

\section{Секвенирование гена гров}

Для амплификации фрагмента гроВ гена размером 322 п.н. использовали праймеры rpoB1 5'-AACCGCCGCCTGCGTA CGGT-3' и rpoB2 5'-GGCCGTAGTGCGACGGGTGCA-3'. Реакционная смесь объемом 25 мкл содержала 65 мМ Tpuc- $\mathrm{HCl}(\mathrm{pH} 8,9), 16 \mathrm{MM}\left(\mathrm{NH}_{4}\right)_{2} \mathrm{SO}_{4}, 3 \mathrm{MM} \mathrm{MgCl}_{2}, 0,05 \%$ Tween-20, 0,2 мМ дНТФ, 1 ед. Таq-полимеразы (Fermentas; Литва), 0,3 мкM вышеуказанных олигонуклеотидных праймеров и 1-10 нг геномной ДНК M. tuberculosis. Амплификацию проводили в амплификаторе РТС-200 (BioRad; США) по следующей программе: $96^{\circ} \mathrm{C}-3$ мин, далее 35 циклов $95^{\circ} \mathrm{C}-10 \mathrm{c}, 64^{\circ} \mathrm{C}-10$ с и $72^{\circ} \mathrm{C}-20 \mathrm{c}$, с финнальной элонгацией $72{ }^{\circ} \mathrm{C}-3$ мин. Присутствие продукта амплификации требуемого размера проверяли электрофорезом в 6\% ПААГ с визуализацией фрагментов ДНК бромистым этидием при облучении ультрафиолетом. Последовательность продуктов ПЦР определяли в ЦКП «Геномика» ИХБФМ СО РАН с использованием реагентов для секвенирования Big Dye Terminator v3.1 Cycle Sequencing Kit (Life Technologies; CШA) и прибора для капиллярного электрофореза ABI 3130xl Genetic Analyzer (Life Technologies; США) согласно инструкциям производителей. Мутации выявляли путем сравнения полученных нуклеотидных последовательностей с геном rроB M. tuberculosis (H37Rv) с помощью программного обеспечения Unipro UGENE software 1.11.3 (Унипро; Россия).

\section{Получение стандартных плазмидных образцов, несущих частые мутации}

Фрагмент ДНК размером 505 п.н. получили с помощью амплификации с олигонуклеотидными праймерами cl-rpobU и cl-rpobR (табл. 1) в следующих условиях: реакционная смесь ПЦР объемом 50 мкл содержала буфер для Таqполимеразы (65 мМ ТрисHCl; $\mathrm{pH} 8,9 ; 16 \mathrm{MM}\left(\mathrm{NH}_{4}\right)_{2} \mathrm{SO}_{4}$; 0,05\% Tween-20; 3,5 мM MgCl2), 0,2 мМ дНТФ, 10 нг геномной ДНК Mycobacterium tuberculosis H37 Rv или ДНК изолята, с мутацией TCG/TTG (S45OL) в гене гроB, 1 е.а. Таq-полимеразы (Биосан; Россия). Амплификацию проводили в амплификаторе Терцик (ДНКтехнология; Россия) согласно следующей программе: 3 мин при $95{ }^{\circ} \mathrm{C}$ для начальной денатурации, далее 34 цикла: 10 с при $95{ }^{\circ} \mathrm{C}$ для денатурации, 10 с при $60{ }^{\circ} \mathrm{C}$ для гибридизации праймеров, 20 с при $72{ }^{\circ} \mathrm{C}$ для элонгации. Продукты амплификации гидролизовали эндонуклеазами рестрикции Hind III и BamHI (Сибэнзим; Россия) и лигировали с вектором pBluescript II SK (+), гидролизованным теми же эндонуклеазами, в течение 8 ч со 100 ед. акт. Т4 ДНК-лигазы (Биосан; Россия). Лигазной смесью трансформировали компетентные клетки E. coli штамма XL1Blue (Stratagene; США). У плазмидных клонов, отобранных по результатам рестрикционного анализа, для подтверждения структуры определяли нуклеотидную последовательность вставки секвенированием по методу Сенгера. Секвенирование выполняли на автоматическом секвенаторе ABI 3130XL GeneticAnalyzer (Applied Biosystems; CШA) C использованием набора BigDye 3.1 (ЦКП «Геномика», ИХБФМ СО РАН; Россия). Рекомбинантные плазмидные ДНК PRPOB-M и PRPOB-W выделяли из 50 мл ночной культуры в среде LB с помощью набора QIAGEN

Таблица 1. Список олигонуклеотидных праймеров и флуоресцентно-меченных зондов, использованных в работе

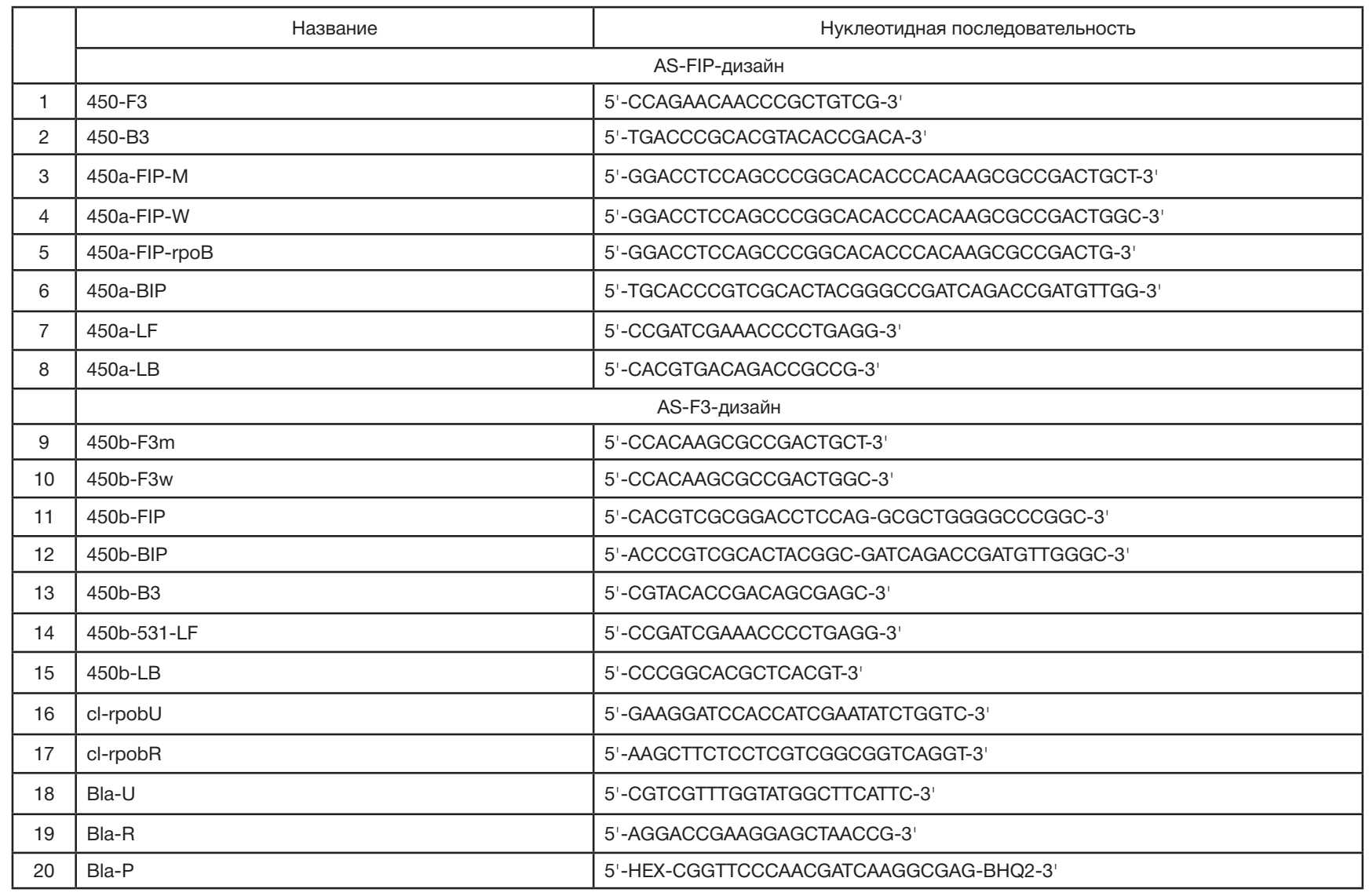


Plasmid Midi Kit (QIAGEN; Германия) согласно инструкции производителя.

Концентрацию полученных стандартных плазмидных ДНК определяли спектрофотометрически и флюорометрически с помощью набора Qubit ${ }^{\mathrm{TM}}$ BR (Invitrogen; США). Далее 2 мкг ДНК подвергали гидролизу эндонуклеазой рестрикции HindllI для линеаризации. Полученные линейные стандарты разводили до концентрации $10^{5}$ и далее до $5 \times 10^{2}$ копий плазмидной ДНК на мкл в стерильном буфере, содержащем 10 мМ Tris $\mathrm{HCl}(\mathrm{pH} 7,6)$ и ДНК фага лямбда 5 нг/МКл.

Концентрацию ДНК в полученных стандартах уточняли с использованием цифровой ПЦР на платсорме QX100 ${ }^{\text {тм }}$ Droplet Digital ${ }^{\mathrm{TM}}$ PCR System (Bio-Rad; СШA) согласно инструкциям производителя. Для этого готовили 20 мкл ПЦР-смеси, содержащей исследуемую ДНК (около 103 копий на 20 мкл), 1× ПЦР-смесь (Bio-Rad; США), 300 нМ олигонуклеотидные праймеры Bla-U, Bla-R и 100 нM TaqMan Bla-P зонд для амплификации гена беталактамазы (табл. 1). Для получения микрокапель 20 мкл приготовленной ПЦР-смеси и 70 мкл масла для генерации капель помещали в соответствующие лунки картриджа DG8. Затем 40 мкл полученных микрокапель переносили на 96-луночную ПЦР-плашку, запечатывали фольгой и помещали в амплисикатор. Была использована следующая программа амплификации: $96^{\circ} \mathrm{C}-10$ мин и далее 50 циклов $96^{\circ} \mathrm{C}-15 \mathrm{c}, 60^{\circ} \mathrm{C}-40$ с с финальным прогревом в течение 10 мин при $98{ }^{\circ} \mathrm{C}$. После этого микрокапли подвергали считыванию с помощью прибора Droplet Reader, полученные данные обрабатывали в программе QuantaSoft (Bio-Rad; CШA).

\section{Изотермическая петлевая амплификация}

Реакционная смесь объемом 20 мкл содержала 1х реакционный буфер (pH 8,0) для Bst-полимеразы (New England Biolabs; США), по 0,2 мкM внешних праймеров (F3/B3), 0,4 мкM петлевых праймеров (LF/BF), 1,2 мкM внутренних праймеров (FIP/BIP), последовательности которых представлены в табл. 1, ДНК-матрицу (1000 копий плазмид или 0,5-2 нг ДНК изолята МТБ на одну реакционную смесь), 2 е.a. Gss-полимеразы из Geobacillus sp. 777 [15]. В случае проведения LAMP в режиме реального времени добавляли интеркалирующий краситель SYTO-9 до концентрации 2 мкM [16]. Реакцию проводили в амплификаторе CFX 96 (Bio-Rad; CША). Программа включала в себя следующие стадии: отжиг праймеров и элонгацию при температуре $60^{\circ} \mathrm{C}$ в течение
80 мин с регистрацией сигнала флюоресценции раз в минуту на канале FAM; определение температуры плавления продуктов амплификации в диапазоне $75-95^{\circ} \mathrm{C}$ после амплисикации для анализа специфичности. Результаты изотермической амплификации оценивали по параметру Tt (time-to-threshold - времени до пересечения кривой накопления продукта амплификации порогового значения). Все реакции LAMP проводили в трех повторах, в таблице указаны средние значения и стандартные отклонения от них.

\section{РЕЗУЛЬТАТЫ ИССЛЕДОВАНИЯ}

Мы использовали две ранее описанные [17, 18] схемы дизайна аллель-специфичной изотермической петлевой амплификации (AS-LAMP) (рис. 1). По первой схеме выявление мутации или аллеля дикого типа осуществляют с помощью двух аллель-специфичных праймеров FIP. По второй схеме аллель-специфичную LAMP инициируют со специсичного для мутации праймера F3. На начальном этапе в качестве матрицы для отработки условий мы использовали плазмиды с клонированным фрагментом гроВ дикого типа и фрагментом, содержащим мутацию. Для оптимизации реакции матрицей для AS-LAMP служил pS450L-M или pS450L-W в концентрации 1000 копий на реакцию. Все реакции оптимизации проводили, отслеживая накопление продуктов изотермической амплификации в режиме реального времени с использованием интеркалирующего красителя SYTO9. В качестве основного параметра для оптимизации использовали индекс дискриминации мутации, который определяли как разность Тt для ДНК «дикого типа» и Тt для мутантной ДНК при использовании для амплификации набора праймеров, в состав которого входит аллель-специсичный праймер (AS-FIP или AS-F3).

В модельных экспериментах на плазмидных ДНК нами было показано, что применение схемы анализа с использованием аллель-специфичного праймера FIP по сравнению с F3 имеет лучший индекс дискриминации мутации: разница между амплификацией мутации и аллеля дикого типа составила $22 \pm 2,4$ против $13 \pm 4,1 \mathrm{мин} \mathrm{(рис.} \mathrm{2).}$ Применение непараметрического U-критерия (критерий Манна-Уитни) показало, что полученные индексы дискриминации отличаются статистически значимо ( $p=0,0011)$. При использовании 100 геном-эквивалентов ДНК истинно положительный сигнал (амплификация гроВ гена с мутацией при использовании соответствующего аллельспецисричного праймера) детектировался после 29,4 + 3,4 мин.

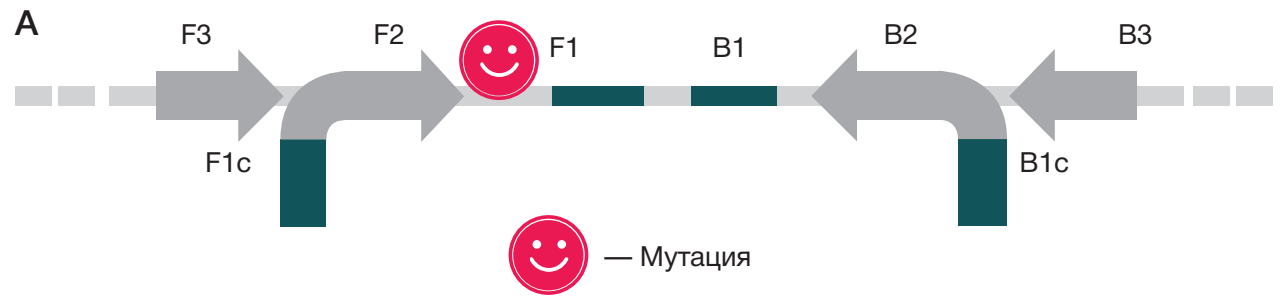

Б

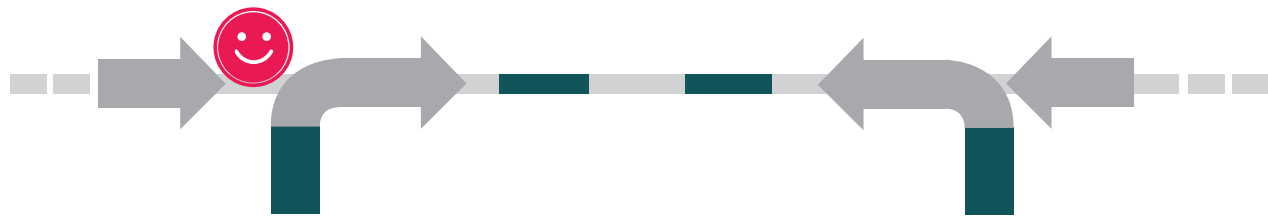

Рис. 1. Схематичное изображение разных принципов аллель-специфичной изотермической петлевой амплификации (AS-LAMP): аллель-специфичный праймер FIP (A), аллель-специфичный праймер F3 (Б) 
Нами были также предприняты попытки улучшения индекса дискриминации мутации с помощью изменения концентрации бетаина, а также путем добавления диметилсульфоксида (ДМСО), который обладает способностью увеличивать специфичность стандартной ПЦР [19]. Оптимальная концентрация бетаина составила 0,75 М, добавление ДМСО не приводило к улучшению дискриминации и даже несколько увеличивало общее время реакции.

Положительный сигнал надежно визуализировали после добавления в реакцию SYBR Green I (в концентрации 1 : 1000 от коммерческого стока красителя), как при освещении дневным светом, так и при использовании трансиллюминатора с УФ-излучением (рис. 3). Для дальнейшей диагностической валидации для каждого тестируемого образца выполняли две реакции: одну AS-LAMP с праймером 531-FIP-M для выявления наличия мутации, другую с праймером 531-FIP-rpoB для определения наличия ДНК МТБ. Реакции выполняли или в термостате при $65^{\circ} \mathrm{C}$ в течение 40 мин с визуализацией результата реакции с помощью SYBR Green I, или в режиме реального времени (см. «Материалы и методы»).

Используя разработанный метод, мы проанализировали выборку ДНК 20 RIFR $^{R}$ изолятов МТБ, несущих мутацию Ser450Leu в гене rpoB, 10 RIFR изолятов, несущих другие мутации в гене гроВ (в частности, в кодонах His445 и

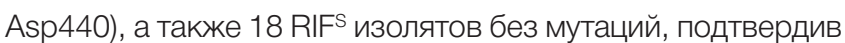
наличие мутаций с помощью секвенирования по Сенгеру (табл. 2). Все исследованные образцы были определены верно, чувствительность и специфичность LAMP для выявления мутации Ser450Leu в гене rроB составили 100\%.

Применение AS-LAMP на небольшой выборке из 11 образцов ДНК из мокроты пациентов с активным бактериовыделением показало полную конкордантность с результатами секвенирования по Сенгеру (4 образца с мутацией и 7 образцов без мутации).

Использование в качестве матрицы ДНК человека не продуцировало значимого сигнала.

Было показано, что анализ может выполняться на грубых лизатах бактериальных клеток. При этом суммарное время проведения анализа начиная с биологического образца может не превышать 1,5 ч, с учетом того, что получение грубых лизатов микобактерий занимает не более 15-30 мин.

\section{ОБСУЖДЕНИЕ РЕЗУЛЬТАТОВ}

В последние несколько лет было предложено несколько подходов к выявлению однонуклеотидных замен ДНК с помощью LAMP. Все они используют аллель-специсичную гибридизацию с продуктами амплисикации [20, 21], аллель-специфичные праймеры [22, 23] также селективно

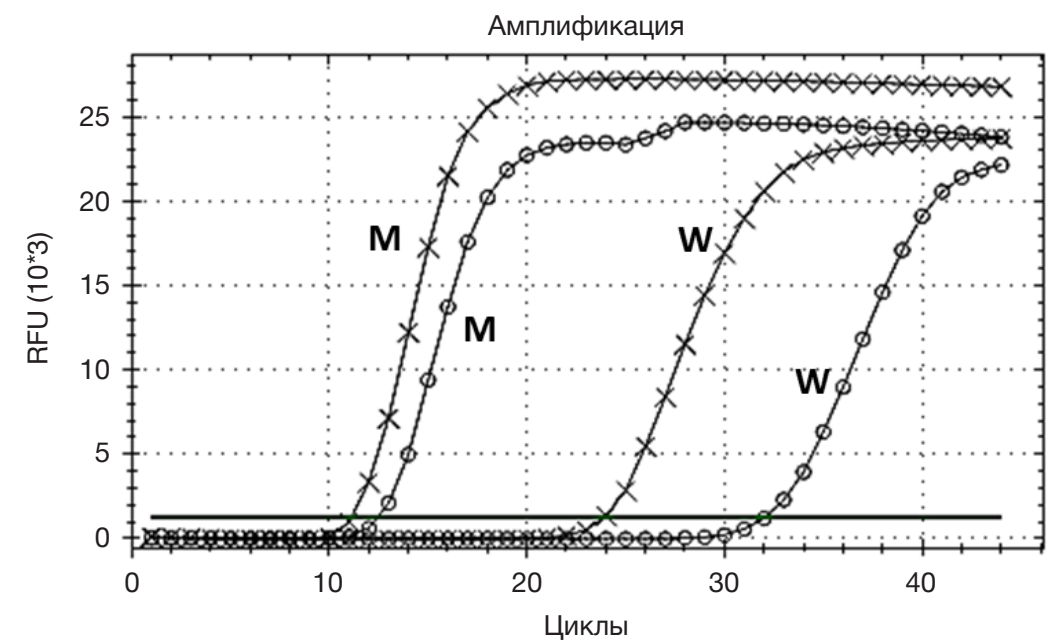

Рис. 2. Кривые накопления фллуоресценции продуктов AS-LAMP. Кривые, выделенные окружностями, соответствуют FIP-AS-LAMP, крестами — F3-AS-LAMP

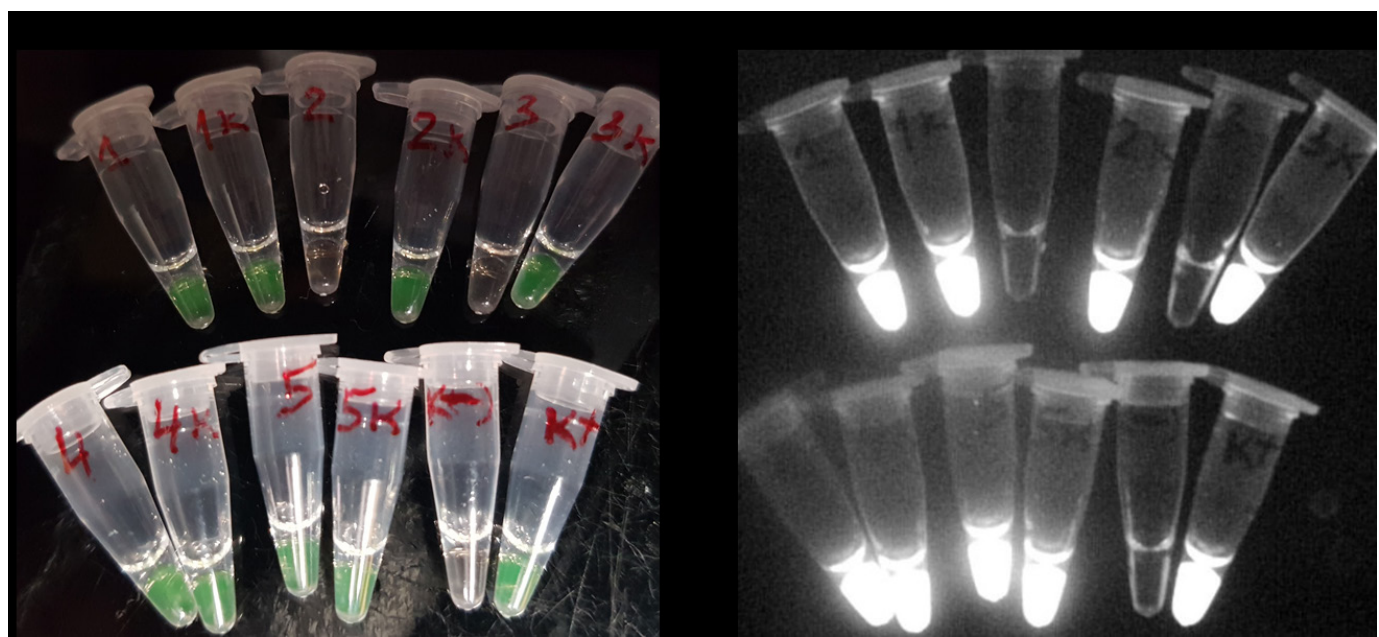

Рис. 3. Выявление мутации TCG/TTG (S450L) гена rроB методом AS-LAMP с визуализацией продуктов амплификации добавлением интеркалирующего красителя SYBR Green I при естественном освещении (A) и UV-освещении 280 нм (Б). Образцы 1, 4, 5 содержат мутацию, 2 и 3 - нет, их амплифицировали с праймером, специфичным для мутации, пробирки с «К» амплифицировали с праймером, специфичным для нормы 
Таблица 2. Спектр выявленных с помощью секвенирования по Сенгеру мутаций гена гроВ у изолятов МТБ и результаты выявления мутации ТСG/ТТG (S450L) с помощью AS-LAMP

\begin{tabular}{|c|l|c|c|}
\hline № & \multicolumn{1}{|c|}{ Мутация } & Секвенирование & AS-LAMP \\
\hline 1 & Нет & 18 & 18 \\
\hline 2 & Ser450Leu (TCG->TTG) & 20 & 20 \\
\hline 3 & His445Leu (CAC->CTC) & 4 & 0 \\
\hline 4 & His445GIn (CAC->CAA) & 1 & 0 \\
\hline 5 & Asp440Val (GAC->GTC) & 3 & 0 \\
\hline 6 & Asp440Asn (GAC->AAC) & 1 & 0 \\
\hline 7 & Asp440His (GAC->CAC) & 1 & 0 \\
\hline
\end{tabular}

блокирующие амплификацию исследуемых структурных вариантов олигонуклеотиды [24].

Аллель-специфичная полимеразная цепная реакция (АС-ПЦР) - один из наиболее широко используемых методов выявления мутаций ДНК [25]. Классический вариант АС-ПЦР предполагает использование двух аллельспецифичных праймеров, в которых 3'-концевой нуклеотид комплементарен полиморфному нуклеотиду, и третьего общего праймера. В основе метода лежит различие эффективности элонгации спаренного и неспаренного 3'-нуклеотида ДНК-полимеразой. В идеальных условиях (при полном ингибировании элонгации) это должно привести к отсутствию продукта амплификации в реакции с праймером к мутации на матрице ДНК дикого типа.

Для улучшения дискриминации продуктов с «мутантной» и «нормальной» ДНК широко используют введение дополнительных неспаренных нуклеотидов на 3'-конце праймера (в позиции -2, -3 или -4) для дальнейшей дестабилизации дуплекса с целью уменьшения эффективности элонгации ДНК-полимеразой. Мы предположили, что при элонгации аллель-специфичных праймеров цепь-вытесняющей ДНК-полимеразой можно использовать схожий принцип. Для дизайна аллельспецифичных праймеров мы выбрали подход, описанный в 2004 г. [26]. Его авторы предложили для увеличения дискриминации мутантного аллеля вводить второй неспаренный нуклеотид в позиции -2 аллель-специсичного праймера, а также простой набор правил выбора типа этого основания для достижения максимального эффекта. Используя данные рекомендации, мы синтезировали два принципиально разных набора AS-праймеров для изотермической петлевой амплификации: один из них соответствует FIP-праймеру, а другой - праймеру F3.

Оптимизация выявления мутации TCG/TTG (S450L) в гене rpoB Mycobacterium tuberculosis на плазмидных контрольных ДНК показала предпочтительность ASFIP. При его использовании мы смогли правильно классифицировать все анализируемые образцы ДНК изолятов МТБ, в том числе как отрицательные по замене TCG/TTG (S45OL) образцы ДНK с мутациями в кодонах 445 и 440, путем визуального анализа результатов изотермической амплификации в стандартном термостате, поддерживающем температуру $65{ }^{\circ} \mathrm{C}$. AS-LAMP также оказался эффективным для выявления мутации Ser450Leu гена гроВ в ДНК из мокроты пациентов с известным статусом мутаций гена гроВ. Нам удалось правильно классифицировать 4 образца с мутацией Ser450Leu и 7 образцов без этой мутации. Предложенный нами подход показал высокую специфичность и чувствительность для выявления наиболее распространенной мутации МТБ, вызывающей резистентность к действию рифампицина. Тем не менее для значимого определения указанных выше параметров необходимо тестирование метода на выборке значительно большего объема.

Несмотря на то что подавляющее число работ, посвященных LAMP, отписывает качественное выявление присутствия инфекционного агента, указанный метод также имеет высокий потенциал для определения структурного полиморфизма анализируемой ДНК. Например, показана возможность определения изолятов семейства Beijing Mycobacterium tuberculosis с использованием в качестве мишеней региона RD207 и гена Rv0679c [27]. Наша работа вносит определенный вклад в развитие методов выявления точечных мутаций с помощью LAMP и также увеличивает исследовательский потенциал указанного метода.

K ограничениям и недостаткам предложенного в настоящей работе метода можно отнести необходимость дополнительной валидации способа экстракции ДНК и связанного с ним количества бактерий ввиду зависимости выбора оптимального времени проведения анализа, при котором позитивный сигнал мутация-специфической системы еще не определяется, от концентрации анализируемой микобактериальной ДНК.

\section{ВЫВОДЫ}

Мы продемонстрировали принципиальную возможность определения мутации TCG/TTG (S450L) в гене rpoB Mycobacterium tuberculosis методом аллельспецифичной изотермической петлевой амплификации с высокой надежностью без применения дорогостоящего оборудования. Суммарное время, необходимое для проведения тестирования клинического образца ДНК, может не превышать 1,5 4.

\section{Литература}

1. Drobniewski FA, Wilson SM. The rapid diagnosis of isoniazid and rifampicin resistance in Mycobacterium tuberculosis - a molecular story. J Med Microbiol. 1998; 47 (3): 189-96.

2. Heifets LB. Antimycobacterial drugs. Semin Respir Infect. 1994; 9 (2): 84-103.

3. TB Drug Resistance Mutation Database. Доступно по ссылке:

https://tbdreamdb.ki.se/Data/MutationDetail.aspx?Areald=RIF\& GenelD=Rv0667.

4. Mokrousov I, Otten T, Vyshnevskiy B, Narvskaya O. Allelespecific rpoB PCR assays for detection of rifampin-resistant Mycobacterium tuberculosis in sputum smears. Antimicrob Agents Chemother. 2003; 47 (7): 2231-5. 
5. Филипенко М. Л., Дымова М. А., Храпов Е. А., Боярских, У. А., Петренко Т. И., Чередниченко А. Г. и др. Способ выявления устойчивых к рифампицину изолятов. Вестник НГУ. 2012; 10 (2): 101-6.

6. Gill P, Ghaemi A. Nucleic acid isothermal amplification technologies: a review. Nucleosides Nucleotides Nucleic Acids. 2008; 27 (3): 224-43.

7. Notomi T, Okayama H, Masubuchi H, Yonekawa T, Watanabe $\mathrm{K}$, Amino $\mathrm{N}$ et al. Loop-mediated isothermal amplification of DNA. Nucleic Acids Res. 2000; 28 (12): E63.

8. Francois P, Tangomo M, Hibbs J, Bonetti E-J, Boehme CC, Notomi $\mathrm{T}$ et. al. Robustness of a loop-mediated isothermal amplification reaction for diagnostic applications. FEMS Immunol Med Microbiol. 2011; 62 (1): 41-8.

9. Mori $\mathrm{Y}$, Nagamine K, Tomita N, Notomi T. Detection of loopmediated isothermal amplification reaction by turbidity derived from magnesium pyrophosphate formation. Biochem Biophys Res Commun. 2001; 289 (1): 150-4.

10. Kouguchi Y, Fujiwara T, Teramoto M, Kuramoto M. Homogenous, real-time duplex loop-mediated isothermal amplification using a single fluorophore-labeled primer and an intercalator dye: Its application to the simultaneous detection of Shiga toxin genes 1 and 2 in Shiga toxigenic Escherichia coli isolates. Mol Cell Probes. 2010; 24 (4): 190-5.

11. Liu W, Huang S, Liu N, Dong D, Yang Z, Tang Y et al. Establishment of an accurate and fast detection method using molecular beacons in loop-mediated isothermal amplification assay. Sci Rep. 2017; (7): 40125.

12. Goto M, Honda E, Ogura A, Nomoto A, Hanaki K-I. Colorimetric detection of loop-mediated isothermal amplification reaction by using hydroxy naphthol blue. Biotechniques. 2009; 46 (3): 167-72.

13. Nagai $\mathrm{K}$, Horita N, Yamamoto M, Tsukahara T, Nagakura $\mathrm{H}$, Tashiro $\mathrm{K}$ et al. Diagnostic test accuracy of loop-mediated isothermal amplification assay for Mycobacterium tuberculosis: systematic review and meta-analysis. Sci Rep. 2016; (6): 39090.

14. World Health Organization, editors. Global Tuberculosis Programme The use of loop-mediated isothermal amplification (TB-LAMP) for the diagnosis of pulmonary tuberculosis: policy guidance. 2016.

15. Oscorbin IP, Boyarskikh UA, Filipenko ML. Large fragment of DNA polymerase I from Geobacillus sp. 777: cloning and comparison with DNA polymerases I in practical applications. Mol Biotechnol. 2015; 57 (10): 947-59.

16. Oscorbin IP, Belousova EA, Zakabunin Al, Boyarskikh UA, Filipenko ML. Comparison of fluorescent intercalating dyes for quantitative loop-mediated isothermal amplification (qLAMP). Biotechniques. 2016; 61 (1): 20-5.

\section{References}

1. Drobniewski FA, Wilson SM. The rapid diagnosis of isoniazid and rifampicin resistance in Mycobacterium tuberculosis - a molecular story. J Med Microbiol. 1998; 47 (3): 189-96.

2. Heifets LB. Antimycobacterial drugs. Semin Respir Infect. 1994; 9 (2): 84-103

3. TB Drug Resistance Mutation Database. Available from: https:// tbdreamdb.ki.se/Data/MutationDetail.aspx?Areald=RIF\&GenelD=Rv0667.

4. Mokrousov I, Otten T, Vyshnevskiy B, Narvskaya O. Allelespecific rpoB PCR assays for detection of rifampin-resistant Mycobacterium tuberculosis in sputum smears. Antimicrob Agents Chemother. 2003; 47 (7): 2231-5.

5. Filipenko ML, Dymova MA, Hrapov EA, Bojarskih, UA, Petrenko TI, Cherednichenko AG i dr. Sposob vyjavlenija ustojchivyh $k$ rifampicinu izoljatov. Vestnik NGU. 2012; 10 (2): 101-6.

6. Gill P, Ghaemi A. Nucleic acid isothermal amplification technologies: a review. Nucleosides Nucleotides Nucleic Acids. 2008; 27 (3): 224-43.

7. Notomi T, Okayama H, Masubuchi H, Yonekawa T, Watanabe $\mathrm{K}$, Amino $\mathrm{N}$ et al. Loop-mediated isothermal amplification of DNA. Nucleic Acids Res. 2000; 28 (12): E63.

8. Francois P, Tangomo M, Hibbs J, Bonetti E-J, Boehme CC, Notomi $T$ et. al. Robustness of a loop-mediated isothermal
17. Badolo A, Bando H, Traoré A, Ko-ketsu M, Guelbeogo WM, Kanuka $\mathrm{H}$ et al. Detection of G119S ace-1 R mutation in fieldcollected Anopheles gambiae mosquitoes using allele-specific loop-mediated isothermal amplification (AS-LAMP) method. Malar J. 2015; (14): 477

18. Carlos FF, Veigas B, Matias AS, Doria G, Flores O, Baptista PV. Allele specific LAMP-gold nanoparticle for characterization of single nucleotide polymorphisms. Biotechnol Reports. 2017; (16): $21-5$

19. Chakrabarti R, Schutt CE. The enhancement of PCR amplification by low molecular-weight sulfones. Gene. 2001; 274 (1-2): 293-8.

20. Jiang YS, Bhadra S, Li B, Wu YR, Milligan JN, Ellington AD. Robust strand exchange reactions for the sequence-specific, real-time detection of nucleic acid amplicons. Anal Chem. 87 (6): 3314-20.

21. Nakamura $\mathrm{N}$, Ito $\mathrm{K}$, Takahashi $\mathrm{M}$, Hashimoto $\mathrm{K}$, Kawamoto $\mathrm{M}$, Yamanaka $M$ et al. Detection of six single-nucleotide polymorphisms associated with rheumatoid arthritis by a loopmediated isothermal amplification method and an electrochemical DNA chip. Anal Chem. 2007; 79 (12): 9484-93.

22. Yongkiettrakul S, Kampeera J, Chareanchim W, Rattanajak R, Pornthanakasem W, Kiatpathomchai W et al. Simple detection of single nucleotide polymorphism in Plasmodium falciparum by SNP-LAMP assay combined with lateral flow dipstick. Parasitol Int. 2017; 66 (1): 964-71.

23. Zhang L, Zhang $Y$, Wang $C$, Feng $Q$, Fan F, Zhang G, et al. Integrated microcapillary for sample-to-answer nucleic acid pretreatment, amplification, and detection. Anal Chem. 2014; 86 (20): 10461-6.

24. Itonaga M, Matsuzaki I, Warigaya K, Tamura T, Shimizu Y, Fujimoto M, et al. Novel methodology for rapid detection of KRAS mutation using PNA-LNA mediated loop-mediated isothermal amplification. PLoS One. 2016; (11): e0151654.

25. Newton CR, Graham A, Heptinstall LE, Powell SJ, Summers C, Kalsheker N, et al. Analysis of any point mutation in DNA. The amplification refractory mutation system (ARMS). Nucleic Acids Res. 1989; 17 (7): 2503-16.

26. Li B, Kadura I, Fu D-J, Watson DE. Genotyping with TaqMAMA. Genomics. 2004; 83 (2): 311-20.

27. Nagai $\mathrm{Y}$, Iwade $\mathrm{Y}$, Nakano M, Akachi $\mathrm{S}$, Kobayashi T, Nishinaka T. Rapid and simple identification of Beijing genotype strain of Mycobacterium tuberculosis using a loop-mediated isothermal amplification assay. Microbiol Immunol. 2016; 60 (7): 459-67.

amplification reaction for diagnostic applications. FEMS Immunol Med Microbiol. 2011; 62 (1): 41-8.

9. Mori Y, Nagamine K, Tomita N, Notomi T. Detection of loopmediated isothermal amplification reaction by turbidity derived from magnesium pyrophosphate formation. Biochem Biophys Res Commun. 2001; 289 (1): 150-4.

10. Kouguchi Y, Fujiwara T, Teramoto M, Kuramoto M. Homogenous, real-time duplex loop-mediated isothermal amplification using a single fluorophore-labeled primer and an intercalator dye: Its application to the simultaneous detection of Shiga toxin genes 1 and 2 in Shiga toxigenic Escherichia coli isolates. Mol Cell Probes. 2010; 24 (4): 190-5.

11. Liu W, Huang S, Liu N, Dong D, Yang Z, Tang Y et al. Establishment of an accurate and fast detection method using molecular beacons in loop-mediated isothermal amplification assay. Sci Rep. 2017; (7): 40125.

12. Goto M, Honda E, Ogura A, Nomoto A, Hanaki K-I. Colorimetric detection of loop-mediated isothermal amplification reaction by using hydroxy naphthol blue. Biotechniques. 2009; 46 (3): 167-72.

13. Nagai $K$, Horita $N$, Yamamoto $M$, Tsukahara $T$, Nagakura $H$, Tashiro $\mathrm{K}$ et al. Diagnostic test accuracy of loop-mediated isothermal amplification assay for Mycobacterium tuberculosis: 
systematic review and meta-analysis. Sci Rep. 2016; (6): 39090.

14. World Health Organization, editors. Global Tuberculosis Programme The use of loop-mediated isothermal amplification (TB-LAMP) for the diagnosis of pulmonary tuberculosis: policy guidance. 2016.

15. Oscorbin IP, Boyarskikh UA, Filipenko ML. Large fragment of DNA polymerase I from Geobacillus sp. 777: cloning and comparison with DNA polymerases I in practical applications. Mol Biotechnol. 2015; 57 (10): 947-59.

16. Oscorbin IP, Belousova EA, Zakabunin Al, Boyarskikh UA, Filipenko ML. Comparison of fluorescent intercalating dyes for quantitative loop-mediated isothermal amplification (qLAMP). Biotechniques. 2016; 61 (1): 20-5.

17. Badolo A, Bando H, Traoré A, Ko-ketsu M, Guelbeogo WM, Kanuka $\mathrm{H}$ et al. Detection of G119S ace-1 R mutation in fieldcollected Anopheles gambiae mosquitoes using allele-specific loop-mediated isothermal amplification (AS-LAMP) method. Malar J. 2015; (14): 477.

18. Carlos FF, Veigas B, Matias AS, Doria G, Flores O, Baptista PV. Allele specific LAMP-gold nanoparticle for characterization of single nucleotide polymorphisms. Biotechnol Reports. 2017; (16): 21-5.

19. Chakrabarti R, Schutt CE. The enhancement of PCR amplification by low molecular-weight sulfones. Gene. 2001; 274 (1-2): 293-8.

20. Jiang YS, Bhadra S, Li B, Wu YR, Milligan JN, Ellington AD. Robust strand exchange reactions for the sequence-specific, real-time detection of nucleic acid amplicons. Anal Chem. 87 (6): 3314-20.

21. Nakamura N, Ito K, Takahashi M, Hashimoto K, Kawamoto M,
Yamanaka $M$ et al. Detection of six single-nucleotide polymorphisms associated with rheumatoid arthritis by a loopmediated isothermal amplification method and an electrochemica DNA chip. Anal Chem. 2007; 79 (12): 9484-93.

22. Yongkiettrakul S, Kampeera J, Chareanchim W, Rattanajak R, Pornthanakasem W, Kiatpathomchai $W$ et al. Simple detection of single nucleotide polymorphism in Plasmodium falciparum by SNP-LAMP assay combined with lateral flow dipstick. Parasitol Int. 2017; 66 (1): 964-71.

23. Zhang L, Zhang $Y$, Wang $C$, Feng $Q$, Fan F, Zhang G, et al. Integrated microcapillary for sample-to-answer nucleic acid pretreatment, amplification, and detection. Anal Chem. 2014; 86 (20): 10461-6.

24. Itonaga M, Matsuzaki I, Warigaya K, Tamura T, Shimizu Y, Fujimoto M, et al. Novel methodology for rapid detection of KRAS mutation using PNA-LNA mediated loop-mediated isothermal amplification. PLoS One. 2016; (11): e0151654.

25. Newton CR, Graham A, Heptinstall LE, Powell SJ, Summers C, Kalsheker $\mathrm{N}$, et al. Analysis of any point mutation in DNA. The amplification refractory mutation system (ARMS). Nucleic Acids Res. 1989; 17 (7): 2503-16.

26. Li B, Kadura I, Fu D-J, Watson DE. Genotyping with TaqMAMA. Genomics. 2004; 83 (2): 311-20

27. Nagai $Y$, Iwade $Y$, Nakano M, Akachi S, Kobayashi T, Nishinaka T. Rapid and simple identification of Beijing genotype strain of Mycobacterium tuberculosis using a loop-mediated isothermal amplification assay. Microbiol Immunol. 2016; 60 (7): 459-67. 